\title{
Crescimento e produtividade da mamoneira irrigada com diferentes diluições de esgoto doméstico tratado ${ }^{1}$
}

\author{
Mário C. de F. Ribeiro ${ }^{2}$, Felizardo A. Rocha ${ }^{3}$, Adailton C. dos Santos ${ }^{2}$, \\ Joseane O. da Silva ${ }^{3}$, Maria de F. S. P. Peixoto ${ }^{4}$ \& Vital P. da S. Paz ${ }^{4}$
}

\begin{abstract}
RESUMO
Objetivou-se avaliar, neste trabalho, os efeitos da irrigação com água de esgoto doméstico sobre as variáveis de crescimento e produtividade da mamoneira, genótipo EBDA MPB 01, em condições de campo. A pesquisa foi realizada no período de dezembro de 2009 a junho 2010, na Universidade Federal do Recôncavo da Bahia, Campus de Cruz das Almas. Foram estudadas quatro diferentes proporções de diluição de esgoto doméstico tratado em comparação com o tratamento testemunha (adubação e irrigação convencional), da seguinte forma: T1 - 100\% do efluente tratado; T2 - 75\% do efluente tratado mais $25 \%$ de água de poço artesiano; T3 - 50\% do efluente tratado mais $50 \%$ de água de poço artesiano; T4 - 25\% do efluente tratado mais $75 \%$ de água de poço artesiano e T5 - manejo convencional (adubação química e irrigação suplementar com água de poço artesiano). O delineamento experimental foi em blocos casualizados (DBC) com quatro blocos cada tratamento, constituindo de 20 parcelas experimentais. A produtividade da mamoneira não apresentou diferença estatística entre os tratamentos. O uso de água residuária de esgoto doméstico na cultura da mamoneira, não afetou as variáveis de crescimento analisadas.
\end{abstract}

Palavras-chave: águas residuárias, reúso, Ricinus communis, produção

\section{Growth and production of castor bean irrigated with different dilutions of domestic wastewater}

\begin{abstract}
The effects of the irrigation with domestic wastewater effluent on the growth variables and the productivity of castor bean, genotyps EBDA MPB 01, were evaluated under field conditions. The research was carried out from December 2009 to June 2010, at UFRB experimental area, in Cruz das Almas, BA. Four different proportions of dilution of domestic wastewater effluent in comparison with the conventional treatment were studied, in the following way: T1 - $100 \%$ of the treated effluent; T2 - $75 \%$ of the effluent $+25 \%$ of artesian well water; T3 - 50\% of the efluent $+50 \%$ of artesian well water; T4 - 25\% of the effluent $+75 \%$ of artesian well water; T5 - conventional treatment (chemical fertilization and supplementary irrigation with water of artesian well). A randomized block design was used with four replications, totaling 20 experimental units. The productivity of the castor been did not show statistical differences among the treatments. The use of wastewater in castor been crop did not affect the growth variables analyzed.
\end{abstract}

Key words: wastewater, reuse, Ricinus communis, yield

\footnotetext{
1 Trabalho apresentado durante a II Reunião Sulamericana para Manejo e Sustentabilidade da Irrigação em Regiões Áridas e Semiáridas, Cruz das Almas, BA - 03 a 07 de abril de 2011

${ }^{2}$ Mestrando, CCAAB/UFRB, Campus de Cruz das Almas, CEP 44380-000, Cruz das Almas, BA. E-mail: maro freitas@yahoo.com.br; agape 323@hotmail.com ${ }^{3}$ IF Bahia/Campus de Vitória da Conquista, Av. Amazonas, n. 3.150, Bairro Zabelê, CEP 45075-265, Vitória da Conquista, BA. Fone: (77) 3426-2271. E-mail: felizardoar@hotmail.com; joseaneos@yahoo.com.br

${ }^{4}$ CCAAB/UFRB. Fone: (75) 3621-2798. E-mail: fatima@ufrb.edu.br; vitalpaz@ufrb.edu.br
} 


\section{INTRODUÇÃO}

A escassez dos recursos hídricos tem-se tornado cada dia mais agravante, tanto no quesito quantidade quanto na sua qualidade. Em contrapartida, os efluentes domésticos e agroindustriais apresentam aumento crescente e, desta forma, podem ser vistos como alternativa de uso potencial na agricultura, ao liberar água de melhor qualidade para fins mais nobres, como o consumo humano e/ou dessedentação de animais, como preconiza a Política Nacional de Recursos Hídricos (Lubello et al., 2004; Souza et al., 2010).

O reúso agrícola de efluentes há várias décadas, é uma prática comum em países como Egito, Austrália, Arábia Saudita, Tunísia, Chile e Israel (Hespanhol, 2002); no último, as águas residuárias são consideradas parte integrante dos recursos hídricos do país a mais de quatro décadas. A reutilização da água doméstica tem sido maciça e hoje Israel reutiliza 75\% dos efluentes gerados, contra 14\% na Espanha, 9\% na Austrália, $8 \%$ na Itália, $5 \%$ na Grécia e menos de $1 \%$ na Europa (Juanicó, 2007). Portanto, a prática do reúso de águas domésticas tratadas tem papel fundamental no planejamento e na gestão sustentável dos recursos hídricos, podendo ser potencialmente utilizada em regiões áridas e semiáridas, como no nordeste brasileiro.

Um dos questionamentos relevantes ao reúso de águas residuárias na agricultura está associado à concentração e ao período de tempo no qual o efluente pode ser aplicado sem causar efeitos maléficos à cultura nem ao solo. Quando a prática do reúso é combinada com o uso de águas salinas na irrigação para produção vegetal, o desafio é ainda maior, exigindo a utilização de espécies tolerantes e adoção de práticas adequadas de manejo da cultura, do solo e da água de irrigação (Rhoades et al., 2000).

As pesquisas brasileiras com reúso de efluentes ainda são recentes e carecem de critérios técnicos claros, elaboração de normativas específicas e desenvolvimento de tecnologias compatíveis com as condições nacionais. Desta forma, os estudos têm focado o reúso em culturas arbóreas e menos restritivas, tais como algodão, flores, girassol e mamona. Essas duas últimas se têm destacado devido à atual conjuntura econômica, estimulando a produção de biodiesel como fonte alternativa de energia (Holanda, 2004).

A mamoneira (Ricinus communis L.) é uma oleagionosa de elevada complexidade morfológica e fisiológica, com crescimento diferenciado em cada ramo, dicotômicos e heterogônicos, com cachos de várias idades fisiológicas, possuindo desenvolvimento heteroblástico e metabolismo fotossintético $\mathrm{C}_{3}$ tratando-se de uma planta rústica, da família das Euforbiaceas, bastante tolerante à seca, e exigente em radiação solar e luminosidade (Carvalho, 2005).

No nordeste brasileiro, há quase 4 milhões de hectares com características edafoclimáticas apropriadas para mamoneira, se alcançaria o rendimento de até 1,5 tha $^{-1}$ (Freitas \& Fredo, 2005). Algumas variedades podem produzir entre $1.500 \mathrm{~kg} \mathrm{ha}^{-1}$ de bagas em regime de sequeiro e até $5000 \mathrm{~kg} \mathrm{ha}^{-1}$ em condições de irrigação (Carvalho, 2005).

Rodrigues et al. (2009) observaram, analisando o crescimento e a produção de bagas de mamoneira (variedades BRS Nordestina e BRS Paraguaçu), que o crescimento da mamoneira foi favorecido pela irrigação com a água residuária de origem doméstica. Em seus estudos, Nascimento et al. (2004) concluíram que a água residuária influenciou significativamente todos os componentes da produção, com destaque para a produção de sementes por planta, que atingiu $630,68 \mathrm{~g} \mathrm{planta}^{-1}$, muito superior à obtida com água de abastecimento, 31,08 g planta $^{-1}$.

Souza et al. (2010) verificaram que as unidades irrigadas com esgoto tratado superaram as irrigadas com água comum e que a produtividade da mamoneira foi maior nos tratamentos irrigados com esgoto tratado mais adubação recomendada e esgoto tratado, mais metade da adubação recomendada, alcançando produtividade de 1.986 e $1.412 \mathrm{~kg} \mathrm{ha}^{-1}$, respectivamente.

O acúmulo continuado de sais no solo resulta em mudanças consideráveis em muitos processos fisiológicos das plantas, tais como: aumento da taxa respiratória e toxicidade por íons, decréscimo do crescimento, instabilidade na membrana plasmática, resultante do deslocamento de cálcio por sódio (Mansour \& Salama, 2004), aumento na permeabilidade da membrana plasmática celular (Gupta et al., 2002) e depleção do teor de clorofila (Kao et al.; 2003; Sayed, 2003).

Os efeitos do uso de águas residuárias nos componentes de produção da mamoneira ainda são pouco compreendidos, principalmente em combinação com a aplicação de água salina. Diante do exposto o objetivo deste trabalho foi avaliar os efeitos de diferentes proporções de diluição do esgoto doméstico tratado nas variáveis de crescimento, componentes de produção e, na produtividade da mamoneira, genótipo EBDA MPB 01.

\section{Material E MÉtodos}

O experimento foi conduzido em área experimental da Universidade Federal do Recôncavo da Bahia - UFRB, Cruz das Almas, BA, de dezembro de 2009 a junho 2010. O clima, de acordo com a classificação de Thornthwaite, é do tipo C1 (seco e subúmido), com precipitação total anual de $1.026 \mathrm{~mm}$ (Almeida, 1999).

O genótipo de mamoneira EBDA MPB01, de porte anão e ciclo de aproximadamente 150 dias, desenvolvido pela Empresa Baiana de Desenvolvimento Agrícola - EBDA, foi cultivado em solo classificado como Latossolo Amarelo (textura média a argilosa).

Antes da implantação do experimento amostras compostas foram retiradas para determinação dos atributos físicos e químicos, nas camadas de 0-20 e 20-40 cm (Tabela 1), conforme metodologias propostas pela EMBRAPA (1997).

O efluente de esgoto doméstico tratado utilizado foi proveniente da estação de tratamento de esgoto do município de Cachoeira, BA, operada pela Empresa Baiana de Águas e Saneamento S.A. (EMBASA), o qual era armazenado em caixas de água de $3000 \mathrm{~L}$.

Durante o período experimental amostras do efluente bruto foram coletadas em recipientes plásticos de $200 \mathrm{~mL}$ após cada irrigação e, ao final de cada mês, feita uma amostra composta, que foi encaminhada para análise química em laboratório. $\mathrm{Na}$ 
Tabela 1. Características físicas e químicas das amostras de solo antes da aplicação dos tratamentos

\begin{tabular}{|c|c|c|c|}
\hline \multirow{2}{*}{ Característica } & \multirow{2}{*}{ Unidade } & \multicolumn{2}{|c|}{ Camada(cm) } \\
\hline & & $0-20$ & $20-40$ \\
\hline Areia grossa & $\left(\mathrm{g} \mathrm{kg}^{-1}\right)$ & 703,0 & 682,0 \\
\hline Silte & $\left(\mathrm{g} \mathrm{kg}^{-1}\right)$ & 76,0 & 71,0 \\
\hline Argila & $\left(\mathrm{g} \mathrm{kg}^{-1}\right)$ & 221,0 & 247,0 \\
\hline Classe textural & & FAA & FAA \\
\hline Densidade do solo & $\left(\mathrm{kg} \mathrm{dm}^{-3}\right)$ & 1,64 & 1,74 \\
\hline Densidade de partícula & $\left(\mathrm{kg} \mathrm{dm}^{-3}\right)$ & 2,46 & 2,31 \\
\hline Porosidade total & $\left(m^{3} m^{-3}\right)$ & 33,41 & 24,75 \\
\hline$-\theta_{c c}$ & $\left(\mathrm{~kg} \mathrm{~kg}^{-1}\right)$ & 0,12 & 0,11 \\
\hline$-\theta_{\mathrm{pmp}}$ & $\left(\mathrm{kg} \mathrm{kg}^{-1}\right)$ & 0,09 & 0,08 \\
\hline Ks & $\left(\mathrm{cm} \mathrm{h}^{-1}\right)$ & 7,90 & 2,85 \\
\hline pH em água (1: 2,5) & & 4,90 & 4,80 \\
\hline P & $\left(\mathrm{mg} \mathrm{dm}^{-3}\right)$ & 16,00 & 2,00 \\
\hline $\mathrm{K}^{+}$ & $\left(\mathrm{cmol}_{\mathrm{c}} \mathrm{dm}^{-3}\right)$ & 0,12 & 0,02 \\
\hline $\mathrm{Na}^{+}$ & $\left(\mathrm{cmol}_{\mathrm{c}} \mathrm{dm}^{-3}\right)$ & 0,10 & 0,02 \\
\hline $\mathrm{Ca}^{2+}$ & $\left(\mathrm{cmol}_{\mathrm{c}} \mathrm{dm}^{-3}\right)$ & 1,20 & 0,80 \\
\hline $\mathrm{Mg}^{2+}$ & $\left(\mathrm{cmol}_{\mathrm{c}} \mathrm{dm}^{-3}\right)$ & 0,60 & 0,60 \\
\hline $\mathrm{H}+\mathrm{Al}$ & $\left(\mathrm{cmol}_{\mathrm{c}} \mathrm{dm}^{-3}\right)$ & 3,00 & 3,52 \\
\hline SB & $\left(\mathrm{cmol}_{\mathrm{c}} \mathrm{dm}^{-3}\right)$ & 2,02 & 1,42 \\
\hline $\mathrm{T}$ & $\left(\mathrm{cmol}_{\mathrm{c}} \mathrm{dm}^{-3}\right)$ & 5,02 & 4,94 \\
\hline PST & (\%) & 1,99 & 0,40 \\
\hline MO & $\left(\mathrm{g} \mathrm{kg}^{-1}\right)$ & 10,70 & 9,52 \\
\hline CEes & $\left(\mu \mathrm{S} \mathrm{cm}^{-1}\right)$ & 120,00 & 68,10 \\
\hline RAS & $\left(\mathrm{mmol} \mathrm{L}^{-1}\right)^{0,5}$ & 0,33 & 0,08 \\
\hline
\end{tabular}

$\theta_{c c}$ - Umidade na capacidade de campo; $\theta_{\text {mp }}$ - Umidade no ponto de murcha permanente; Ks Condutividade hidráulica saturada; SB - Soma de bases; T - Capacidade de troca catiônica a pH 7,0; PST - percentagem de sódio trocável; MO - teor de matéria orgânica pelo método de WalkleyBlack; CEes - condutividade elétrica do extrato de saturação; RAS - Razão de adsorção de sódio; FAA - Franco argilo-arenosa

Tabela 2 são exibidos os resultados da análise química resultante da amostra composta do efluente bruto tratado e da análise da água de irrigação utilizada nas diluições.

O delineamento experimental foi em blocos casualizados, com cinco tratamentos e diferentes proporções de diluição:

Tabela 2. Características físico-químicas médias do efluente de esgoto doméstico tratado (EET) e da água do poço artesiano (AP) utilizada no experimento

\begin{tabular}{|c|c|c|c|c|}
\hline Constituintes & Unidade & $\mathrm{AP}^{(3)}$ & EET $^{(3)}$ & VMRE \\
\hline $\mathrm{pH}$ & & 7,52 & 6,50 & 6,8 a $7,3^{(1)}$ \\
\hline $\mathrm{Ca}^{2+}$ & $\left(\mathrm{mg} \mathrm{L}^{-1}\right)$ & 169,94 & 86,57 & 20 a $120^{(2)}$ \\
\hline $\mathrm{Mg}^{2+}$ & $\left(\mathrm{mg} \mathrm{L}^{-1}\right)$ & 222,77 & 78,80 & 10 a $50^{(2)}$ \\
\hline $\mathrm{K}^{+}$ & $\left(\mathrm{mg} \mathrm{L}^{-1}\right)$ & 16,00 & 51,00 & 10 a $40^{(2)}$ \\
\hline $\mathrm{Na}^{+}$ & $\left(\mathrm{mg} \mathrm{L}^{-1}\right)$ & 56,00 & 140,00 & 50 a $250^{(2)}$ \\
\hline C.E & $\left(\mathrm{dS} \mathrm{m}^{-1}\right)$ & 2,92 & 1,42 & 1,0 a $3,1^{(1)}$ \\
\hline P-total & $\left(\mathrm{mg} \mathrm{L}^{-1}\right)$ & 0,02 & 4,15 & --- \\
\hline N-total & $\left(\mathrm{mg} \mathrm{L}^{-1}\right)$ & 0,70 & 35,00 & 10 a $50^{(2)}$ \\
\hline Alcalinidade & $\left(\mathrm{mg} \mathrm{L}^{-1} \mathrm{CaCO}_{3}\right)$ & 756,60 & 510,41 & --- \\
\hline Dureza total & $\left(\mathrm{mg} \mathrm{L}^{-1} \mathrm{CaCO}_{3}\right)$ & 798,00 & 540,00 & --- \\
\hline Cloreto & $\left(\mathrm{mg} \mathrm{L}^{-1}\right)$ & 812,98 & 48,00 & 40 a $200^{(2)}$ \\
\hline $\mathrm{HCO}_{3}^{-}$ & $\left(\mathrm{mg} \mathrm{L}^{-1}\right)$ & 922,47 & 1698,52 & -- \\
\hline DBO & $\left(\mathrm{mg} \mathrm{L}^{-1}\right)$ & 6,70 & 155,00 & 812,98 \\
\hline $\mathrm{DQO}$ & $\left(\mathrm{mg} \mathrm{L}^{-1}\right)$ & 10,00 & 269,00 & 922,47 \\
\hline CT & $\left(\mathrm{NMP} 100 \mathrm{~mL}^{-1}\right)$ & $1,5 \times 10^{2}$ & $1,3 \times 10^{6}$ & --- \\
\hline CF & $\left(\mathrm{NMP} 100 \mathrm{~mL}^{-1}\right)$ & $<1,0$ & $<1,0$ & --- \\
\hline RAS & $\left.(\mathrm{mmol} \mathrm{L})^{-1}\right)^{0,5}$ & 0,66 & 2,61 & 4,5 a $7,9^{(2)}$ \\
\hline Relação Ca:Mg & & 0,76 & 1,10 & --- \\
\hline Relação DBO:DQ0 & & 0,67 & 0,58 & $2,4^{(1)}$ \\
\hline
\end{tabular}

P-total - Fósforo total; N-total - Nitrogênio total; CO - Carbono orgânico; DQO - Demanda Química de Oxigênio; DBO - Demanda Bioquímica de Oxigênio; N-total - nitrogênio total; P-total - fósforo total; CT - coliformes totais; CF - coliformes termotolerantes (Fecais - E. coli); VMRE - valor médio de referência para esgoto tratado; (1) Pescod (1992); (2) Feigin et al. (1991); ${ }^{(3)}$ média de seis valores
T1 - 100\% do efluente tratado (ET); T2 - 75\% ET mais 25\% de água de poço artesiano (AP); T3 - 50\% ET mais 50\% AP; $\mathrm{T} 4$ - 25\% ET) mais 75\% AP); T5 - manejo convencional (MC), adubação química e irrigação suplementar com água de poço artesiano, conforme recomendação de Medeiros et al. (2005), constituídos de quatro blocos, totalizando vinte parcelas experimentais. As parcelas possuíam área de $16 \mathrm{~m}^{2}(4 \mathrm{x} 4 \mathrm{~m})$ cada uma, com 10 plantas úteis, espaçadas $1,0 \mathrm{~m}$ entre linhas e $0,5 \mathrm{~m}$ entre plantas. Cada parcela tinha 5 linhas de plantas, sendo as duas linhas laterais externas consideradas bordadura e as três linhas centrais consideradas linhas úteis, nas quais foram efetuadas as avaliações.

$\mathrm{Na}$ adubação convencional (T5) foram aplicados $50 \mathrm{~kg} \mathrm{ha}^{-1}$ de N (10 kg ha-1 no plantio e $40 \mathrm{~kg} \mathrm{ha}^{-1} \mathrm{em}$ cobertura), $50 \mathrm{~kg} \mathrm{ha}^{-1}$ de $\mathrm{P}_{2} \mathrm{O}_{5}$ e $25 \mathrm{~kg} \mathrm{ha}^{-1}$ de $\mathrm{K}_{2} \mathrm{O}$, com base na análise química prévia do solo. As fontes de $\mathrm{P}_{2} \mathrm{O}_{5}, \mathrm{~K}_{2} \mathrm{O}$ e N utilizadas foram o superfosfato simples, cloreto de potássio e uréia, respectivamente.

O efluente líquido tratado foi armazenado em uma caixa de água de 3000 L e diluído com o auxílio de outras três caixas de água de $2000 \mathrm{~L}$, de forma a implementar os tratamentos T1, T2, $\mathrm{T} 3 \mathrm{e} \mathrm{T} 4$.

O critério adotado na definição das lâminas de irrigação com água residuária (aplicadas por um sistema de gotejamento) na implantação dos tratamentos, baseou-se na evapotranspiração da cultura da mamona. Para estimativa das necessidades hídricas das culturas, foram instalados um Tanque Classe A, pluviômetro e estação meteorológica automática na área experimental, para monitoramento das condições meteorológicas. A frequência da aplicação da água residuária foi com turno de rega diário, realizando-se manutenção periódica do sistema de irrigação para evitar entupimentos e alteração na uniformidade de distribuição de água dos emissores.

As informações climáticas (precipitação acumulada, temperatura e umidade relativa evaporação acumulada) mensais registradas durante o experimento, estão listadas na Tabela 3.

Tabela 3. Valores mensais de totais precipitados acumulados (PA), temperatura média (TM), umidade relativa média (URM) e evaporação acumulada do Tanque Classe A (ECA) durante o período experimental

\begin{tabular}{lcccc}
\hline \multicolumn{1}{c}{ Mês } & $\begin{array}{c}\text { PA } \\
(\mathbf{m m})\end{array}$ & $\begin{array}{c}\text { TM } \\
\left({ }^{\circ} \mathbf{C}\right)\end{array}$ & $\begin{array}{c}\text { URM } \\
(\mathbf{\%})\end{array}$ & $\begin{array}{c}\text { ECA } \\
(\mathbf{m m})\end{array}$ \\
Dezembro & 0 & 26,53 & 68,13 & 107,05 \\
Janeiro & 0 & 26,60 & 68,83 & 159,64 \\
Fevereiro & 38,9 & 26,55 & 72,82 & 148,31 \\
Março & 98,8 & 26,49 & 77,33 & 147,81 \\
Abril & 208,4 & 24,76 & 83,86 & 117,68 \\
Maio & 105,0 & 24,17 & 89,71 & 120,22 \\
Junho & 62,0 & 22,23 & 85,26 & 90,34 \\
\hline
\end{tabular}

Na avaliação dos tratamentos foram realizadas análises de crescimento e produtividade da cultura, durante todo o ciclo. A análise de crescimento foi realizada quinzenalmente, a partir dos 21 dias após a emergência das plântulas até o final do ciclo, totalizando 12 épocas de amostragem. Foram quantificadas as variáveis: diâmetro da haste na altura do colo, denominado diâmetro do caule (DC), número de folhas (NF) e 
altura das plantas (AP). Para número de cachos (NC), a avaliação foi iniciada 78 dias após a emergência, totalizando 8 épocas de amostragem. Para essas avaliações foram selecionadas e identificadas com etiqueta, dez plantas por parcela, com características fenológicas semelhantes, e analisadas de forma não destrutiva.

Em todos os tratamentos a área foliar da mamoneira foi realizada na fase de maturação utilizando-se o aparelho medidor de área foliar portátil AM 300 (ADC Scientific). O aparelho consta de uma prancheta e um pequeno scanner de mão, acoplado a um microcomputador dedicado, fornecendo os valores de área diretamente.

A produção de bagas foi estimada analisando-se 10 plantas úteis por parcela. As colheitas foram feitas quando os cachos apresentavam pelo menos 4 bagas secas; posteriormente, os cachos foram secados ao sol e os grãos limpos e acondicionados em sacos de papel; em seguida e se considerando a umidade dos grãos e a área útil da parcela, estimou-se a produtividade da mamoneira em $\mathrm{kg} \mathrm{ha}^{-1}$.

As variáveis de crescimento da mamoneira foram avaliadas por meio de análise de variância, tendo-se como fontes tratamento $(\mathrm{T})$ e épocas de amostragem $(\mathrm{E})$ e a interação TxE; continuando, a análise de regressão foi realizada entre as variáveis de crescimento (DC, NF, AP e NC) em função das épocas de amostragem, ou seja, dias após a semeadura (DAS).

Adicionalmente ao final do experimento e em cada tratamento, foram analisadas as componentes de produção, número de bagas por planta (NB), número de bagas por racemo (NBR), peso médio de sementes por planta (PS) (g), número de sementes por planta (NS) e peso médio de 100 sementes por tratamento (P100), em gramas.

Os dados de variáveis de crescimento e componentes de produção, tal como de produtividade da mamoneira, foram submetidos à análise de variância (ANOVA) seguidos da comparação das médias, pelo teste de Tukey, a 5\% de probabilidade, e análise de regressão em função da época de amostragem. As análises estatísticas foram efetuadas empregando-se o software SAEG, desenvolvido pela Universidade Federal de Viçosa, MG.

\section{RESULTADOS E DISCUSSÃO}

Com relação às variáveis de crescimento, altura de planta (AP) e número de folhas (NF) observou-se efeito significativo para os tratamentos testados $(\mathrm{p}<0,01)$, exceto para a variável diâmetro de caule (DC), na qual não foram constatados efeitos significativos (Tabela 4); apesar disto, a interação T x E não foi significativa, ou seja, o manejo convencional e o uso de água de esgoto doméstico aplicada em diferentes proporções com água do poço artesiano ao longo do tempo não afetou o crescimento da mamoneira para as variáveis DC, APe NF.

Verifica-se, pelo teste de comparação entre médias, que para diâmetro do caule não houve diferença estatística entre os tratamentos, o que não foi observado para as variáveis altura de planta e número de folhas (Tabela 5). A aplicação de 100\% $\mathrm{ET}, 75 \% \mathrm{ET}+25 \%$ AP e o tratamento com manejo convencional,
Tabela 4. Resumo da análise de variância das variáveis diâmetro do caule (DC), altura da planta (AP) e número de folhas (NF) da mamona, em função dos tratamentos

\begin{tabular}{lrlcc}
\hline \multirow{2}{*}{ FV } & \multicolumn{4}{c}{ Quadrado médio } \\
\cline { 2 - 5 } & GL & \multicolumn{1}{c}{ DC } & \multicolumn{1}{c}{ AP } & NF \\
Tratamento (T) & 4 & $0,01755600 \mathrm{~ns}$ & $781,4283^{* *}$ & $71,25694^{* *}$ \\
Época (E) & 11 & $5,850885^{* *}$ & $9323,788^{* *}$ & $731,8255^{* *}$ \\
Tx E & 44 & $0,03067548 \mathrm{~ns}$ & $26,99022 \mathrm{~ns}$ & $4,849597 \mathrm{~ns}$ \\
Bloco & 3 & $2,138863^{* *}$ & $2513,472^{\star *}$ & $154,4997^{* *}$ \\
Resíduo & 177 & 0,06539285 & 76,91103 & 7,361963 \\
Média & & 1,8643 & 41,172 & 15,580 \\
C.V.(\%) & \multicolumn{2}{c}{13,71} & 21,30 & 17,41 \\
\hline
\end{tabular}

significativo a $0,01\left(^{\star \star}\right)$ de probabilidade (ns) não significativo

Tabela 5. Valores médios de diâmetro do caule - DC $(\mathrm{mm})$, altura de planta - AP (cm) e número de folhas (NF) da mamoneira submetido a irrigação com diferentes diluições com água de esgoto doméstico tratado

\begin{tabular}{lccc}
\hline \multicolumn{1}{c}{ Tratamentos } & $\begin{array}{c}\text { DC } \\
(\mathbf{m m})\end{array}$ & $\begin{array}{c}\text { AP } \\
\mathbf{( c m )}\end{array}$ & NF \\
$\mathrm{T} 1=100 \% \mathrm{ET}$ & $1,85 \mathrm{a}$ & $42,52 \mathrm{a}$ & $15,47 \mathrm{~b}$ \\
$\mathrm{~T} 2=75 \% \mathrm{ET}+25 \% \mathrm{AP}$ & $1,86 \mathrm{a}$ & $43,46 \mathrm{a}$ & $16,14 \mathrm{ab}$ \\
$\mathrm{T} 3=50 \% \mathrm{ET}+50 \% \mathrm{AP}$ & $1,84 \mathrm{a}$ & $37,53 \mathrm{~b}$ & $15,38 \mathrm{~b}$ \\
$\mathrm{~T} 4=25 \% \mathrm{ET}+75 \% \mathrm{AP}$ & $1,89 \mathrm{a}$ & $36,43 \mathrm{~b}$ & $13,78 \mathrm{c}$ \\
$\mathrm{T} 5=\mathrm{MC}$ & $1,87 \mathrm{a}$ & $45,90 \mathrm{a}$ & $17,11 \mathrm{a}$ \\
\hline
\end{tabular}

Médias seguidas de letras minúsculas iguais na coluna não diferem entre si, pelo teste Tukey a $5 \%$ de probabilidade

ET - efluente tratado; AP - água de poço artesiano

diferiram estatisticamente dos demais tratamentos, para altura de planta. Esta diferença significou um aumento médio de $16,72 \%$ a mais na altura do tratamento $\mathrm{T} 1$, em relação ao tratamento T4.

Rodrigues et al. (2009) observaram, trabalhando com aplicação de água residuária doméstica na cultura da mamoneira, que a altura das plantas cresceu de forma mais acentuada entre 48 e 90 DAS, diminuindo de intensidade no período seguinte e voltando a ser um pouco mais intensa no último período entre 132 e 174 DAS.

No entanto, Lima et al. (2007) constataram, estudando a influência da salinidade na cultivar BRS 149-Nordestina, que a mesma foi sensível à presença de sais na água de irrigação com tendência a diminuir o desenvolvimento vegetativo, com o aumento da salinidade da água de irrigação. O excesso de sais no solo diminui o potencial da água dificultando a absorção de água pelas raízes (Pinheiro et al., 2008), além de causar desequilíbrio nutricional na planta (Gurgel et al., 2005).

$\mathrm{O}$ efluente tratado apresentou concentração média de $\mathrm{N}$ total de $35 \mathrm{mg} \mathrm{L}^{-1}$, elemento este mais demandado no processo de crescimento da mamoneira, corroborando com Rodrigues et al. (2009) que, trabalhando com água residuária doméstica na cultura da mamona, encontraram valores médios de $31,50 \mathrm{mg} \mathrm{L}^{-1}$.

Em todos os tratamentos analisados a variável número de folhas atingiu seu valor máximo aos 121 DAS, declinando após este período em virtude, provavelmente, do processo de senescência.

A aplicação do manejo convencional diferiu estatisticamente dos tratamentos T1, T3 e T4 para número de folhas com incremento de $10,60,11,24$ e $24,16 \%$, respectivamente, porém sem apresentar diferença estatística no tratamento T2. Sofiatti 
et al. (2007) observaram aumento no número de folhas em algodoeiro com a aplicação de lodo de esgoto, comportamento inverso ao observado neste estudo, quando o diâmetro do caule atingiu valor máximo em torno de $2,50 \mathrm{~cm}$ (180 DAS), com média de $1,86 \mathrm{~cm}$. Severino et al. (2006) observaram, trabalhando com adubação química na cultivar BRS Nordestina, devido ao excessivo crescimento vegetativo, que o diâmetro do caule das plantas foi maior, com média de $4,0 \mathrm{~cm}$, enquanto nas plantas que não receberam a adubação o diâmetro do caule foi de $3,26 \mathrm{~cm}$.

Rodrigues et al. (2009) constataram, em estudo com reúso de águas residuárias domésticas na cultura da mamona (BRS Paraguaçu e BRS Nordestina), que o diâmetro caulinar da mamoneira cresce de forma mais acentuada até três meses após o plantio e que os dados foram semelhantes entre as cultivares. Neste trabalho após 151 DAS, os tratamentos T4 e T5 mantiveram tendência de crescimento do DC, enquanto os demais tratamentos permaneceram constantes.

Tanto os tratamentos como a interação T x E apresentaram efeito significativo para $\mathrm{NC}$, ou seja, em diferentes épocas de amostragem a aplicação de diferentes proporções do efluente doméstico, influenciou no número de cachos (Tabela 6).

Tabela 6. Resumo da análise de variância e do número de cachos (NC) da mamoneira quando submetido a diferentes diluições do esgoto doméstico

\begin{tabular}{lrc}
\hline \multirow{2}{*}{ FV } & \multicolumn{2}{c}{ Quadrado médio } \\
\cline { 2 - 3 } Tratamento $(\mathrm{T})$ & GL & NC \\
Época (E) & 4 & $0,8812498^{* *}$ \\
TxE & 7 & $11,41385^{* *}$ \\
Bloco & 28 & $0,08728571^{* *}$ \\
Resíduo & 3 & $1,251229^{* *}$ \\
Média & 177 & 0,07033166 \\
C.V. (\%) & & 1,8031 \\
\hline
\end{tabular}

significativo a $0,01\left(^{* \star}\right)$ de probabilidade (ns) não significativo
De acordo com a Figura 1, observou-se efeito linear crescente no número de cachos da mamoneira para todos os tratamentos, sendo que a aplicação de maiores concentrações de efluente tratado influenciou no maior número de cachos. Nos tratamentos analisados os cachos surgiram a partir de 78 DAS e mostraram tendência de crescimento, mesmo após os 180 DAS. Por outro lado, o genótipo de mamona emitiu a primeira inflorescência aos 64 DAS.

Os coeficientes de determinação $\left(\mathrm{R}^{2}\right)$ da variável $\mathrm{NC}$ foram superiores a 0,90, constatando-se uma forte relação entre a variável estudada e o tempo, após a emergência das plantas.

O genótipo de mamona EDBA MP02, embora precoce e com ciclo de 120 dias, continuou a emitir cachos até os 180 DAS, quando se encerrou o experimento. A irrigação diária com água residuária estimulou o desenvolvimento vegetativo apesar dos sais presentes na água de irrigação, fato também constatado por Severino et al. (2006) e Rodrigues et al. (2009). Os autores relataram que a disposição excessiva de esgoto doméstico mediante irrigação, pode aumentar o crescimento vegetativo, retardar a maturação ou provocar colheitas de baixa qualidade.

Neste estudo não houve comparação entre os tratamentos testados com água de qualidade para se averiguar o real efeito nas variáveis de crescimento da cultura; no entanto, existem, na literatura, vários relatos de redução na taxa de crescimento das variáveis AP, DC e NF da mamoneira, irrigadas com águas salinas (Cavalcanti et al.; 2005; Lima et al., 2007; Silva et al., 2008). Esses autores observaram, analisando o desenvolvimento e a produção de duas cultivares de mamoneira sob estresse salino submetido a quatro níveis de $\mathrm{CE}$ da água de irrigação (entre $0,7 \mathrm{dS} \mathrm{m} \mathrm{m}^{-1}$ a 6,7 $\mathrm{dS} \mathrm{m}{ }^{-1}$ ), reduções lineares entre os valores de AP, DC e NF, para as cultivares de BRS Paraguaçu e BRS Energia.

Nos diferentes tratamentos estudados a área foliar da mamoneira foi realizada na fase de maturação, ao final do ciclo da cultura. Observou-se que o tratamento T2 (75\% de ET mais

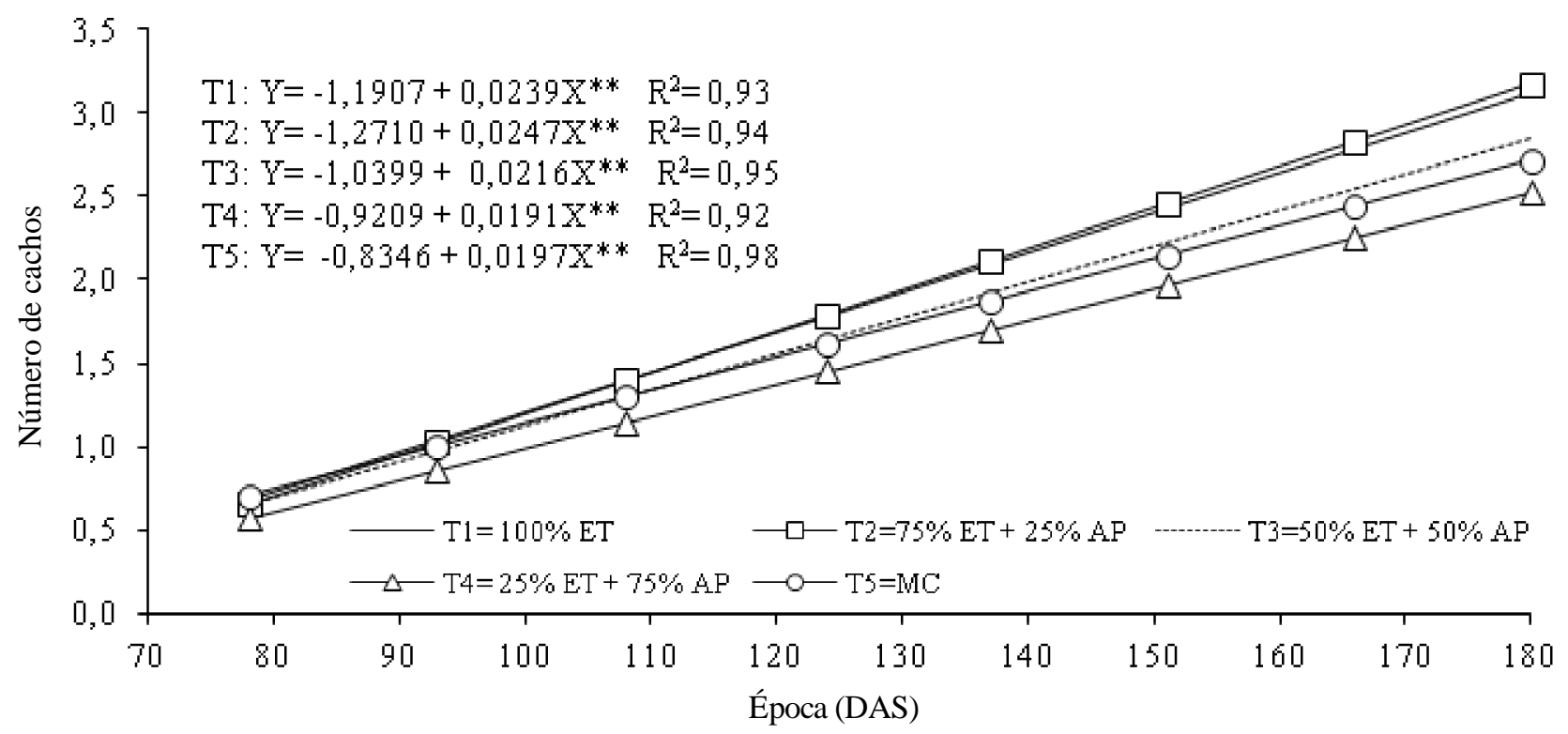

T1 - 100\% do efluente tratado (ET); T2 - 75\% ET mais 25\% de água de poço artesiano (AP); T3 - 50\% ET mais 50\% AP; T4 - 25\% ET) mais 75\% AP); T5 - manejo convencional (MC)

Figura 1. Número de cachos da mamoneira em função da época de amostragem, submetido a diferentes diluições da água residuária de esgoto doméstico tratado 


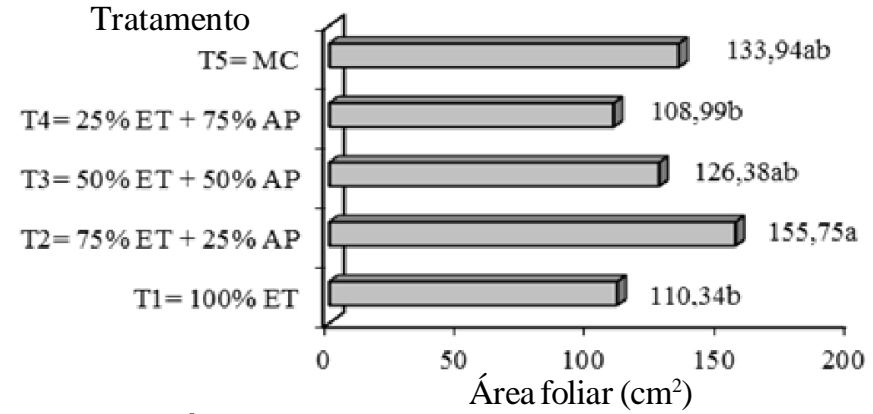

Figura 2. Área foliar da mamoneira na fase de maturação submetido a diferentes diluições da água residuária de esgoto doméstico (ET) com água do poço artesiano (AP)

$25 \%$ AP) diferiu dos tratamentos T1(100\% de ET) e T4 (25\% de ET mais 75\% de AP) (Figura 2), mas não diferiu estatisticamente dos tratamentos T3 (50\% ET + 50\% AP) e T5 (manejo convencional).

Por outro lado, os tratamentos que apresentaram maior número de folhas (T2 e T5) foram os que também apresentaram maiores valores de área foliar.

Barreto et al. (2008) notaram, trabalhando com água residuária de esgoto doméstico na cultura da mamona, que a área foliar foi maior com a aplicação de água residuária em comparação com a água de abastecimento e com a mistura das duas, corroborando com Nascimento et al. (2006), de que a água residuária de esgoto doméstico promoveu um incremento nos valores da área foliar da mamona, em todas as fases avaliadas.

No que se refere aos componentes de produção da mamoneira, as diferentes diluições da água residuária não foram significativas pelo teste $\mathrm{F}$ (Tabelas 7 e 8), evidenciando o potencial de substituição de parte da adubação química pela água residuária de esgoto doméstico tratado, além de economia no consumo do recurso água de qualidade. Apesar do resultado promissor é preciso avaliar os efeitos de longo prazo (em vários ciclos da cultura) da prática do reúso agrícola da água residuária no solo e na planta. Além disso se observou, embora não tenha havido diferença significativa, que o tratamento testemunha (T5) apresentou produtividade de até $32,14 \%$ maior que os tratamentos empregando esgoto doméstico tratado (T1 a T4), impossibilitando definir o percentual exato de substituição da adubação química pelo uso de esgoto doméstico tratado. Este efeito pode estar associado às causas de variações no ambiente e/ou material experimental, além das fontes aleatórias de variação (erro experimental).

A produtividade média da mamona também não apresentou diferença estatística quando as diluições da água residuária de esgoto doméstico variaram, tal como o tratamento com manejo convencional (adubação química) (Figura 3).

Severino et al. (2006) verificaram, avaliando a cultivar BRS Nordestina submetida a adubação química, um aumento na produtividade de $1.072 \mathrm{~kg} \mathrm{ha}^{-1}$ para $2.298 \mathrm{~kg} \mathrm{ha}^{-1}$ com o fornecimento de adubo nitrogenado; ressalta-se que neste trabalho a produtividade média da mamoneira foi de 1.302 kg ha-1.

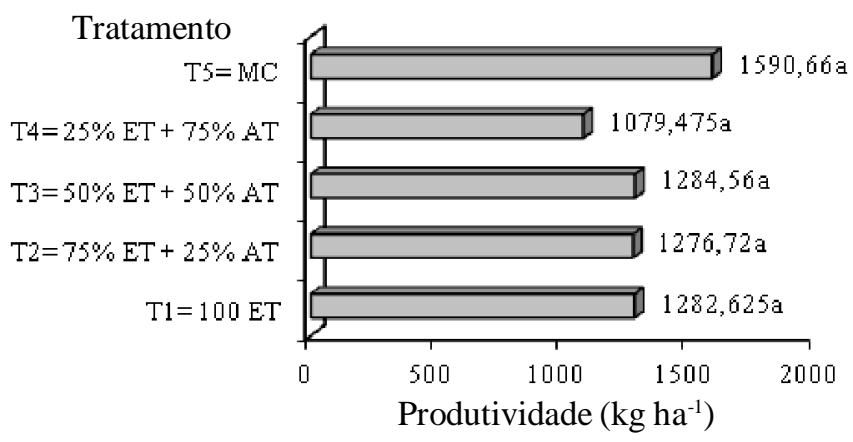

Figura 3. Produtividade média da mamona $\left(\mathrm{kg} \mathrm{ha}^{-1}\right)$ submetida a diferentes diluições da água residuária de esgoto doméstico tratado (ET) com água de poço artesiano (AP)

Tabela 7. Resumo da análise de variância dos componentes de produção da mamoneira (número de bagas planta ${ }^{-1}$ $(\mathrm{NB})$, número de bagas racemo ${ }^{-1}$ (NBR), peso médio de sementes planta ${ }^{-1}(\mathrm{PS})$ (g), número de sementes planta-1 (NS) e peso médio de 100 sementes(P100) (g)) submetida a irrigação com diferentes diluições com água de esgoto doméstico tratado

\begin{tabular}{lcccccc}
\hline \multirow{2}{*}{ F.V. } & \multirow{2}{*}{ G.L. } & \multicolumn{5}{c}{ Quadrado médio } \\
\cline { 3 - 7 } & & NB & NBR & PS & NS & P100 \\
Tratamento & 4 & $158,7595^{\text {ns }}$ & $17,6399^{\text {ns }}$ & $335,3947^{\text {ns }}$ & $1428,836^{\text {ns }}$ & $338,4500^{\text {ns }}$ \\
Bloco & 3 & $676,7134^{\text {ns }}$ & $75,1904^{\text {ns }}$ & $997,7853^{\text {ns }}$ & $6090,422^{\text {ns }}$ & $433,1167^{\text {ns }}$ \\
Resíduo & 12 & 466,6884 & 51,8542 & 889,0596 & 4200,197 & 491,7834 \\
C.V. (\%) & & 40,66 & 40,66 & 45,77 & 40,66 & 7,56 \\
Média & & 53,12 & 17,70 & 65,14 & 159,38 & 293,35 \\
\hline
\end{tabular}

ns - Não significativo pelo teste F

Tabela 8. Valores médios de número de bagas planta ${ }^{-1}(\mathrm{NB})$, número de bagas racemo-1 (NBR), número de sementes planta $^{-1}$ (NS), peso médio de sementes $\operatorname{planta}^{-1}(\mathrm{~g})$ e peso médio de 100 sementes P100 (g) da mamoneira submetida a irrigação com diferentes diluições, com água de esgoto doméstico tratado

\begin{tabular}{lccccc}
\hline Tratamentos & NB & NBR & NS & PS & P100 \\
T1 $=100 \% \mathrm{ET}$ & $54,93 \mathrm{a}$ & $18,31 \mathrm{a}$ & $164,80 \mathrm{a}$ & $64,13 \mathrm{a}$ & $28,2 \mathrm{a}$ \\
$\mathrm{T} 2=75 \% \mathrm{ET}+25 \% \mathrm{AP}$ & $50,59 \mathrm{a}$ & $16,86 \mathrm{a}$ & $151,77 \mathrm{a}$ & $63,84 \mathrm{a}$ & $28,5 \mathrm{a}$ \\
$\mathrm{T} 3=50 \% \mathrm{ET}+50 \% \mathrm{AP}$ & $55,97 \mathrm{a}$ & $18,65 \mathrm{a}$ & $167,91 \mathrm{a}$ & $64,23 \mathrm{a}$ & $30,0 \mathrm{a}$ \\
$\mathrm{T} 4=25 \% \mathrm{ET}+75 \% \mathrm{AP}$ & $43,74 \mathrm{a}$ & $14,58 \mathrm{a}$ & $131,22 \mathrm{a}$ & $53,97 \mathrm{a}$ & $29,5 \mathrm{a}$ \\
$\mathrm{T} 5=$ MC & $60,39 \mathrm{a}$ & $20,13 \mathrm{a}$ & $181,19 \mathrm{a}$ & $79,63 \mathrm{a}$ & $30,3 \mathrm{a}$ \\
\hline
\end{tabular}

Médias seguidas de letras minúsculas iguais na coluna, não diferem entre si, pelo teste Tukey, a $5 \%$ de probabilidade 
Neste experimento foi realizada apenas adubação química no tratamento testemunha (manejo convencional) em que fornecimento de nutrientes se destinou ao crescimento da mamoneira e para os demais tratamentos retirados, na sua maior parte, da água residuária utilizada na irrigação, sobretudo nitrogênio, nutriente de maior importância para o crescimento das plantas. $\mathrm{O}$ aporte de nitrogênio total no efluente de esgoto variou entre 24,90 a 60,00 $\mathrm{mg} \mathrm{L}^{-1}$ (Tabela 2), semelhante aos valores encontrados por Medeiros et al. (2005).

\section{Conclusões}

1. As diferentes diluições da água residuária de esgoto doméstico aplicada na cultura da mamoneira, influenciaram as variáveis de crescimento altura de planta e número de folhas, com exceção da variável diâmetro do caule.

2. A aplicação do efluente de esgoto doméstico tratado, proporcionou boa produtividade em comparação com a adubação química convencional, evidenciando potencial de uso da água residuária de esgoto doméstico tratado, com economia no consumo da água de qualidade.

\section{Agradecimentos}

Os autores agradecem à FAPESB, pelo financiamento da pesquisa, à Universidade Federal do Recôncavo da Bahia (UFRB), pela oportunidade de realização da pesquisa e ao Núcleo de Engenharia de Água e Solo (NEAS), pelo apoio, no que se refere à infraestrutura para realização da pesquisa.

\section{LITERATURA CITADA}

Almeida, O. A. Informações meteorológicas do CNP: Mandioca e Fruticultura Tropical. Cruz das Almas: Embrapa CNPMF. 1999. 35p. Documentos, 34

Barreto, A. N.; Nascimento, J. J. V. R.; Nóbrega, J. A.; Medeiros, E. P.; Bezerra, J. R. C. Influência da água residuária sobre o crescimento da mamoneira BRS energia. In: In: Congresso Brasileiro de Mamona, 3, 2008, Salvador. Anais... Campina Grande: Embrapa Algodão, 2008. CD Rom

Carvalho, B. C. L. Manual do cultivo da mamona. Salvador: EDBA, 2005. 65p.

Cavalcanti, L. F. M.; Fernandes, P. D.; Gheyi, H. R.; Júnior, G. B.; Soares, F. A. L.; Siqueira, E. C. Índices ecofisiológicos da mamoneira sob estresse salino. Revista Brasileira de Engenharia Agrícola eAmbiental, v.91, p.66-70, 2005.

EMBRAPA - Empresa Brasileira de Pesquisa Agropecuária. Centro Nacional de Pesquisa de Solos. Manual de métodos de análise de solo. 2.ed. Rio de Janeiro: Embrapa CNPS, 1997. 212p. Documentos, 1.

Feigin, A.; Ravina, I.; Shalhevet, J. Irrigation with treated sewage efluent. Berlin: Spring-Verlang. 1991. 216p. Advanced Series in Agricultural Science
Freitas, S. M. de.; Fredo, C. E. Biodiesel à base de óleo de mamona: Algumas considerações. Revista Informações Econômicas, v.35, p.37-42, 2005.

Gupta, N. K., Meena, S. K., Gupta, S., Khandelwal, S. K. Gas exchange, membrane permeability, and ion uptake in two species of Indian jujube differing in salt tolerance. Photosynthetica, v.40, p.535-539. 2002.

Gurgel, M. T.; Fernandes, P. D.; Santos, F. J. de S.; Gheyi, H. R.; Bezerra, I. L.; Nobre, R. G. Estresse salino na germinação e formação de porta-enxerto de aceroleira. Revista Brasileira de Engenharia Agrícola e Ambiental, v.7, p.31-36, 2003.

Hespanhol, I. Potencial de reúso de água no Brasil - Agricultura, indústria, municípios e recarga de aquíferos. Revista Brasileira de Recursos Hídricos, v.7, p.75-95, 2002.

Holanda, A. Biodiesel e inclusão social. Brasília: Câmara dos Deputados, Coordenação de Publicações, 2004. 200p. Série Cadernos de altos estudos, n. 1

Juanicó, M. Reutilización de águas residuales. Qué se puede aprender de la experiencia israelí. Revista Tecnologia del Água, n.285, p.58-67. 2007.

Kao, W. Y., Tsai, T. T., Shih, C. N. Photosynthetic gas exchange and chlorophyll $a$ fluorescence of three wild soybean species in response to $\mathrm{NaCl}$ treatments. Photosynthetica, v.41, p.415419.2003.

Lima, C. B.; Santos Filho, S. V. dos.; Santos, M. A.; Oliveira, M. de. Influência da água salina nas características físicoquímicas do solo e no desenvolvimento da mamoneira cultivada em vasos. Caatinga, v.20, p.132-136, 2007.

Lubello, C.; Gori, R.; Incise, F. P.; Ferrini, F. Municipal-treated wastewater reuse for plant nurseries irrigation. Water Research, v.38, p.2939-2947, 2004.

Mansour, M. M. F., Salama, K. H. A. Cellular basis of salinity tolerance in plants. Environmental Experimental Botany. v.52, p.113-122. 2004.

Medeiros, S. de S.; Soares, A. A.; Ferreira, P. A.; Souza, J. A. A.; Matos, A. T. Comportamento dos atributos químicos do solo em resposta à aplicação de água residuária de origem doméstica. Revista Brasileira de Engenharia Agrícola e Ambiental, v.9, p.268-273, 2005.

Nascimento, M. B. H.; Lima, V. L. A.; Beltrão, N. E. M.; Souza, A. P.; Figueirêdo, I. C. M.; Lima, M. M. Uso de biossólido e de água residuária no crescimento e desenvolvimento da mamona. Revista Brasileira de Oleaginosas e Fibrosas, v.10, p.1001-1007, 2006.

Pescod, M. B. Wastewater treatment and use in agriculture. Rome: FAO, 1992. 125p. FAO - Irrigation and Drainage Paper, 47

Pinheiro, H., A.; Silva, J. V.; Endres, L.; Ferreira, V. M.; Câmara, C. A.; Cabral, F. F.; Oliveira, J. F.; Carvalho, L. W. T. de; Santos, J. M. dos; Filho, B. G. dos. Leaf gas exchange, chloroplastic pigments and dry matter accumulation in castor bean (Ricinus communis L.) seedlings subjected to salt stress conditions. Industrial Crops and Products, v.27, p.385-392, 2008.

Rhoades, J.; Kandiah, A.; Mashali, A. M. Uso de águas salinas para produção agrícola. Campina Grande: UFPB. 2000. 117p. Estudos FAO Irrigação e Drenagem 48

Rodrigues, L. N.; Nery, A. R.; Fernandes, P. D.; Beltrão, N. E. de M.; Gheyi, H, R. Crescimento e produção de bagas da mamoneira irrigada com água residuária doméstica. Revista Brasileira Engenharia Agrícola Ambiental, v.13, p.825-835, 2009. 
Sayed, O. H. Chlorophyll fluorescence as a tool in cereal crop research. Photosynthetica, v.41, p.321-330, 2003.

Severino, L. S.; Ferreira, G. B.; Moraes, C. T. de A.; Gondim, T. M. de S.; Freire, S. de A.; Castro, D. A. de.; Cardoso, G. D.; Beltrão, N. E. de M. Crescimento e produtividade da mamoneira adubada com macronutrientes e micronutrientes. Pesquisa Agropecuária Brasileira, v.41, p.563-568, 2006.
Silva, S. M. S.; Alves, A. N.; Gheyi, H. R.; Beltrão, N. E. de M.; Severino, L. S.; Soares, F. A. L. Desenvolvimento e produção de duas cultivares de mamoneira sob estresse salino. Revista Brasileira deEngenhariaAgrícolaeAmbiental, v.12, p.335-342, 2008. Souza, N. C.; Mota, S. B.; Bezerra, F. M. L.; Aquino, B. F.; Santos, A. B. Produtividade da mamona irrigada com esgoto doméstico tratado. Revista Brasileira Engenharia Agrícola Ambiental, v.14, p.478-484, 2010. 